\title{
As Trilhas da refacção textual de uma estudante de EJA captadas pelo software Camtasia e pelo editor de texto Word
}

\section{Text re-writing tracks of an EJA student captured by Camtasia software and Word text editor}

\author{
Adelma Lúcia de Oliveira Silva Araújo* \\ Margareth de Souza Freitas Thomopoulos**
}

\begin{abstract}
RESUMO
Este artigo aborda o uso do software Camtasia e do editor de texto do Word como instrumentos auxiliares para a descrição dos procedimentos de refacção textual digital de um relato autobiográfico produzido por um sujeito adulto do sexo feminino em fase de alfabetização. O método utilizado é o descritivo, com abordagem qualitativa, e a metodologia é a do estudo de caso. Enquanto o software Camtasia captura as pistas deixadas na escrita da tela digital do editor de texto Word, mostrando as ações realizadas pelo sujeito em seu trabalho com o texto, os recursos da revisão de texto do Word permitem perceber fatos singulares da escrita da aprendiz e levantar outros relacionados ao percurso traçado por ela em sua manipulação da língua. Assim, a cada momento em que a aprendiz reelabora, aceita ou não a marcação do software e escolhe o que considera a melhor solução para um problema percebido, evidencia-se seu trabalho ativo na construção e reconstrução do aprendizado, com independência, autonomia e protagonismo. A conclusão de nossa pesquisa aponta para a relevância do uso de novas tecnologias como facilitadoras do acesso aos dados singulares fundamentais para a compreensão do processo de ensino-aprendizagem.
\end{abstract}

Palavras-chave: Alfabetização. Consciência Fonológica. Tecnologias na Educação. Software Camtasia. Atividade Epilinguística.

* Universidade Federal de Ouro Preto. E-mail: adelmaa@yahoo.com.br. https://orcid. org/0000-0001-8503-7096.

** Universidade Tecnológica Federal do Paraná. E-mail: msfthom@gmail.com. https:// orcid.org/0000-0003-3631-4442. 


\begin{abstract}
This article discusses the use of Camtasia software and Word text editor as auxiliary instruments for describing textual re-writing procedures in an autobiographical account produced by a female adult in literacy phase. The method used is descriptive, with a qualitative approach and a case study methodology. While the software Camtasia captures the clues left in the writing of digital screen of text editor Word, showing the actions taken by the subject in her work with the text, the proofing features of Word allow us to realize unique writing facts of apprentice's writing and raise other stroke path related to the course charted by her in language manipulation. So, every time the apprentice reworks, accepts or not the software's markup and chooses what she considers the best solution to a perceived problem, it is evidenced her active work on the construction and reconstruction of learning, with independence, autonomy and protagonism. The conclusion of our research points to the importance of the use of new technologies as facilitators of access to unique data fundamental to the understanding of the teaching-learning process.
\end{abstract}

Keywords: Literacy. Phonological Awareness. Technology in Education. Camtasia Software. Epilinguistic Activity.

\title{
Introdução
}

Ao longo das últimas décadas, muitas pesquisas têm sido desenvolvidas com o objetivo de investigar a influência do uso do computador no processo de alfabetização de crianças e adultos. Se há, por um lado, os que rejeitam a utilização desse instrumento no processo educacional, por outro, existem os defensores da inserção das tecnologias na instituição escolar, fundamentando sua defesa em resultados de pesquisas que mostram os benefícios do seu uso nas práticas pedagógicas atuais.

Uma das vozes contrárias à inserção desses instrumentos tecnológicos no ensino, que discute o tema a partir do projeto "Um laptop por criança", é a de Setzer (2009), professor do Departamento de Ciência da Computação da Universidade de São Paulo. Em defesa do seu ponto de vista, o autor analisa esse projeto, originado no Media Laboratório do M.I.T. - E.U.A., um dos mais importantes centros de pesquisa nas áreas de engenharia e tecnologia do mundo. 
No cerne do projeto, está Nicholas Negroponte ${ }^{1}$, que, juntamente com Seymour Papert (1993), defendem a acessibilidade dos estudantes à tecnologia para elevar o progresso educacional das crianças. Na defesa de seu ponto de vista contrário ao dos autores, Setzer se vale de resultados de várias pesquisas desenvolvidas em diversas partes do mundo, tomando como protagonistas aquelas que estudam o uso do computador por jovens aprendizes, crianças e adultos, como é o caso da pesquisa de Armstrong \& Casement (2001), que analisa o uso do software WTR (Writing to Read) como auxiliar do desenvolvimento de habilidades de leitura e escrita em crianças da educação infantil até o $1^{\mathrm{o}}$ ano. Os resultados dessa pesquisa mostraram que o uso do computador cria um condicionamento nos aprendizes avaliados, não apresentando benefícios satisfatórios na mudança de padrão de leitura e escrita.

Outra pesquisa considerada por Setzer é a de Angrist \& Lavy (2002, apud SETZER, op.cit.) em escolas públicas de Israel, que analisou o uso do software Tomorrow na modalidade de ensino Computer-Aided Instruction - CAI, em que a utilização do computador ou suplementa o que o professor ensinou ou substitui as formas tradicionais de instrução. Os autores concluíram que não há qualquer evidência de que o CAI (Computer-Aided Instruction) melhora significativamente a educação.

Setzer menciona ainda a investigação desenvolvida por Dwyer et al. (2007), que analisaram se havia uma correlação entre o uso de computador e o desempenho escolar de alunos de $4^{\mathrm{a}}$ e $8^{\mathrm{a}}$ séries do Ensino Fundamental e da $3^{\text {a }}$ série do Ensino Médio. Os dados foram os das pesquisas do Sistema de Avaliação do Ensino Básico do Brasil (doravante SAEB) de 2001. Os resultados mostraram não haver uma associação positiva entre o uso do computador e o desempenho dos alunos caso estes realizem as atividades sem a contextualização, explicação e orientação dos professores. Esses estudos permitiram também a percepção de que os métodos de ensino baseados apenas no uso do computador pelos alunos de forma independente e sem a mediação do professor se mostram menos efetivos do que os métodos tradicionais.

Já Sprietsma (2007) se debruçou sobre os dados do SAEB, nos anos de 1999, 2001 e 2003, com o objetivo de verificar se o uso do computador, associado ao uso da internet nas escolas, especificamente pelos alunos da $8^{\mathrm{a}}$ série, elevaria os resultados dos testes de matemática e escrita. Os resultados de seu estudo validaram aqueles citados anteriormente, sinalizando que a associação do laboratório de computação na escola e do uso do computador nessa modalidade não altera significativamente os resultados de matemática e leitura. Entretanto, apontou haver a promoção do desenvolvimento de competências e da inclusão

1 Fundador e presidente da organização sem fins lucrativos One Laptop per Child. 
social do indivíduo, objetivos educacionais defendidos pela Organização das Nações Unidas para a Educação, a Ciência e a Cultura (doravante Unesco).

Contrariamente aos dados discutidos acima, a autora mostra que há, sim, um aumento nos escores dos testes de matemática e leitura dos alunos quando o professor faz uso do computador e da internet como recurso pedagógico. Esse melhor desempenho dos alunos quando monitorados pelo professor enfatiza a importância dessa mediação durante as atividades, assim como a problematização da própria atividade, dando-se significação ao uso do computador para a execução do exercício, variáveis cruciais para o sucesso dos resultados encontrados em sua investigação.

Observando-se as pesquisas supramencionadas, pode-se perceber nelas um denominador comum: em todas, o aluno fazia uso do computador em um laboratório, de forma independente, solitária, sem a mediação de um professor. Isto é, o estudante realizava suas atividades sem uma contextualização, explicação ou orientação do professor. Tais resultados trouxeram à luz dados relevantes, mostrando que os métodos de ensino baseados apenas no uso do computador de forma independente pelos alunos, sem a mediação do professor, parecem ser menos efetivos do que os métodos tradicionais.

Essa correlação entre o uso do computador (associado à internet), o papel do professor (mediador/orientador) e a avaliação do aprendiz é o tema a ser abordado no presente artigo. Os dados analisados provêm do trabalho de refacção textual realizado por uma empregada doméstica, adulta, aluna de EJA, ao escrever sua autobiografia utilizando o computador, mais especificamente $\mathrm{o}$ editor de texto do Word. Buscou-se aqui seguir a trilha de Gonçalves (2007), que desenvolveu uma pesquisa com o objetivo de analisar as contribuições da utilização do computador na alfabetização e na pós-alfabetização de jovens e adultos por meio de depoimentos dos educandos. Uma das mais importantes contribuições de um trabalho dessa natureza diz respeito à oportunidade que os aprendizes têm de, ao usarem o computador durante seus estudos, refletir sobre o seu processo de alfabetização e pós-alfabetização, compreendendo as particularidades que caracterizam a linguagem oral e a distinguem da linguagem escrita, bem como o papel de ambas na constituição dos sujeitos em consonância com seus vários papéis sociais.

Temos como premissa a consideração de que existem hodiernamente apenas duas atitudes (opostas) possíveis dos profissionais da educação no que tange ao uso de novas tecnologias em sala de aula: (i) reconhecer que boa parte dos educandos já se mostra proficiente no domínio das novas tecnologias e, então, incorporar à sua prática um aparato tecnológico como elemento estimulador/ potencializador do aprendizado; (ii) fechar os olhos às peculiaridades da nova geração de aprendizes, desconsiderando seus saberes prévios e o espaço social 
ocupado pelas novas tecnologias, apegando-se às remotas memórias da didática pautada na tecnologia de lousa e giz.

Este trabalho se apoia na primeira perspectiva, por acreditarmos que, tanto na sala de aula quanto fora dela, o computador e os aplicativos educacionais já se constituem em ferramentas relevantes para a pesquisa e o fazer educativo. Ademais, comungamos da opinião de Coscarelli (1998, 2010a, 2010b) de que a função de desenvolver o letramento digital é do professor, e isso se dá a partir da implementação de projetos que estejam "conectados" ao mundo dos alunos.

$\mathrm{Na}$ análise que aqui se faz, o computador, associado ao aplicativo de gravação de tela Camtasia, versão 7.0, foi usado como uma ferramenta tecnológica em prol da avaliação processual da aprendizagem da informante ao digitar e redigitar seu relato autobiográfico ${ }^{2}$, previamente elaborado no caderno. O uso do software ajuda a compreender o que ocorre com os erros ortográficos, produzidos pela informante-aprendiz na versão manuscrita, no momento em que ela refaz seu relato autobiográfico no computador. As gravações do Camtasia e as transcrições do processo de refacção textual das versões do seu relato autobiográfico fornecem valiosas pistas para a análise implementada, permitindo a observação de seus gestos e reflexões em voz alta durante o processo de digitação do texto. Particularidades foram observadas tanto no manuscrito, quanto na versão digitada (inserções, omissões, apagamentos, reescritas, trocas ou exclusões totais de segmentos). No entanto, foi o uso da tecnologia digital que permitiu a percepção e descrição da ação cognitiva reflexiva empreendida pela informante durante $\mathrm{o}$ ato da escritura de segmentos e palavras na composição de seu texto (MARINHO, A. R. P.; ARAÚJO, A. L. O. S.; THOMOPOULOS, M. S. F., 2012).

No presente opúsculo, busca-se apresentar algumas nuanças do processo de letramento digital, no que tange ao aprimoramento da escrita da informante a partir do uso do computador na elaboração de sua autobiografia. $\mathrm{Na}$ análise qualitativa, destacamos os indícios de sua consciência da norma ortográfica.

\section{Contextualizando}

Inicialmente é importante esclarecer como se deu a inserção da tecnologia digital na vida da informante. Esta recebeu de presente de sua patroa um notebook para dar prosseguimento ao seu relato autobiográfico, outrora apenas quirografado. Embora se mostrasse ansiosa para escrever seu relato, a informante

2 Os Dados aqui analisados foram coletados e cedidos por ARAÚJO (2014). 
dizia estar sem forças para "pegar caderno e lápis para escrever." O texto do relato fora digitado e ela, então, começou a trabalhar a cronologia desse texto, denominado $2^{\mathrm{a}}$ versão.

As sessões de reescritura aconteceram na casa de sua patroa. Nessas ocasiões, ao digitar, ela questionava os recursos do processador de texto Word. A cada trabalho com o texto, a informante engendrava dados preciosos sobre suas descobertas e sobre o uso da ferramenta de revisão do editor de texto. Ela já havia feito, criteriosamente, em casa, a leitura e a marcação das passagens que seriam integradas a três fases cronológicas de sua vida: infância, adolescência e fase adulta. Simultaneamente, havia realizado algumas correções nas palavras do relato.

Conquanto a informante já houvesse nomeado sua autobiografia por temas, ainda havia algumas inadequações, como, por exemplo, relatos de fatos pertencentes à infância juntamente com dados da fase adulta ou, ainda, informações da fase adulta misturadas às da adolescência. Para organizar esse texto, lançou mão da seguinte estratégia: marcar o trecho a ser transportado, copiá-lo e colá-lo no lugar devido. Ela havia aprendido, na sessão anterior, que, se um texto fosse copiado e colado, não desapareceria do arquivo. Descobriu também que palavras marcadas com um traço vertical vermelho indicavam apagamento futuro ou cópia e colagem em outro lugar (ressalte-se, aqui, que o recurso ora descrito é o de correção do Word). Durante esse trabalho de cópia e colagem do texto, a aprendiz questionou sua interlocutora (sua patroa, professora de língua portuguesa) sobre o porquê de não se dizer deletar em vez de controlar alterações. As explicações referentes a esses conceitos foram fornecidas e logo compreendidas.

A informante continuava o trabalho com o texto que, embora fosse a organização cronológica do relato, implicava a manipulação de diversas ferramentas e o aprendizado de certas funções do editor, o que acarretou consequências imediatas, tais como: (i) a percepção de alguns vocábulos contendo erros ortográficos e com formas oscilantes, (ii) o aprendizado das múltiplas funções do recurso de revisão de texto; (iii) a troca de papéis durante a correção do texto: ora como escritora-leitora ora como leitora-escritora e (iv) a descoberta, como leitora, de que o texto precisava de algumas reelaborações.

A consideração do "antes e depois" da correção textual usando o editor de texto pode levar a uma avaliação das etapas de elaboração, reelaboração e reflexão sobre como se dá o processo de construção do conhecimento pelo aluno. Isto já pode ser visto em muitos textos manuscritos, ou seja, neles é possível perceber as marcas das reelaborações gravadas no papel por seus escritores; no entanto, na escrita quirografada, não se logra descobrir como eram as formas anteriores àquelas apagadas. As marcas ou processos de reelaboração - grifo, cobertura 
total da palavra à caneta ou a lápis, apagamento ou sobrescrita - ocorrem tanto na folha manuscrita, quanto em um texto digitado no computador quando se usa o recurso de revisão textual. A diferença entre um e outro é a possibilidade aberta por este último de que a sequência de atos seja gravada, permitindo uma análise processual da escrita, o que não é possível na escrita em folha de papel. Aí reside a importância da gravação de uma sessão de reelaboração: permitir ver e rever, fazer observações sobre o processo assistido e traçar uma trilha de todas as ações executadas pelo aprendiz durante o trabalho com seu texto. Além disso, possibilita a observação do estado inicial da palavra e o seu estado final após as modificações realizadas. O trabalho de análise de uma sessão de reelaboração do texto será o centro de nossa discussão. Os exemplos foram extraídos da versão digitada.

\section{Os Dados epilinguísticos}

Levantemos, inicialmente, uma sequência de ações referentes à correção ortográfica. Em determinado momento, a informante percebe uma separação vocabular errônea. Assim, retira os espaços entre "pai" e "zana", gerando "paizana". Em outro ponto do relato, faz uma leitura do trecho e corrige o vocábulo "timar", apagando o grafema "-m", e substituindo-o pelo dígrafo "nh" + "a" ("-nha"), gerando a forma "tinhaar". Após concluir a ação, relê a palavra e descobre a duplicação dos as; retorna ao cursor, apaga o "-ar" que tinha restado da palavra original e deixa a palavra "tinha". Neste movimento de leitura e trabalho de escrita com seu texto disposto visualmente no ecrã do computador, a informante demonstra sua consciência fonológica da sílaba e das unidades intrassilábicas. A permuta de segmentos evidencia o processo consciente de apropriação das regras que permeiam a língua escrita. $\mathrm{O}$ despertar dessa consciência das inadequações das palavras escritas pode ter sido ativado pelo editor de textos por meio do recurso de sublinhar em vermelho as palavras com possíveis problemas ortográficos. Assim, a partir dos grifos do editor, a informante procede às alterações de segmentos, evidenciando sua percepção das unidades fonológicas que compõem a palavra, as quais eram transpostas, alteradas ou permutadas até que a palavra fosse confirmada pelo Word como sendo aceita ou possível na língua (ADAMS et al., 2006, p. 21).

Durante a análise dos fenômenos fonético-fonológicos do relato, embora tenhamos verificado que a informante não tinha, ainda, o domínio de regras que governam o uso dos elementos gráficos "ch" e "x", percebeu-se, na transcrição 
desse trecho do relato, que havia uma oscilação no uso desses elementos em alguns vocábulos, como nos casos apresentados a seguir. A informante procede à correção da palavra "xamado", trocando o "x" por "ch". Após ter feito a alteração, faz novamente a leitura do trecho corrigido, percebendo então que ficaram dois "as"; retorna e apaga a letra "a", conferindo mais uma vez o resultado final: "chamado". Na mesma página, corrige os vocábulos "xegava" > "chegava" e "axei" > "achei", apagando a letra "x" e digitando em seu lugar o dígrafo "ch". Nessa segunda ação da informante sobre o texto, fez-se notar sua compreensão de que, para se escrever uma palavra ortograficamente correta, há que se analisar sua estrutura sonora. Tal compreensão se fez perceptível pela estratégia de falar em voz alta o vocábulo. Este, segundo Bryant \& Bradley (1987), Capovilla \& Capovilla (2000), é um importante passo no processo de formação da consciência fonológica, que se manifesta na conscientização de que a fala pode ser segmentada e seus segmentos manipulados.

Outras correções ortográficas foram observadas, tais como: inserção do grafema "i" após o "m", no vocábulo "comgo"; apagamento da palavra "tinha" e nova digitação do trecho "ele agora já esta sifalando comgo minha tia tinha mi falado...". A informante reconhece ainda a escrita desviante do vocábulo "ajente": apaga o grafema "j" e digita em seu lugar o grafema correto "g"; também percebe a inadequação da hipossegmentação "disque", inserindo uma separação vocabular entre o verbo ("dis") e a preposição ("que"). Quanto à forma desviante "dis", considere-se que o segmento final é um complicador no processo de aquisição da escrita, pois o grafema " $z$ " não condiz com a sua pronúncia desvozeada nesse contexto de final de palavra. A percepção da segmentação vocabular desviante foi também verificada no trecho "omeu pai", que, de forma firme e atenta, foi corrigida por ela ao colocar o cursor depois da letra "o", introduzindo um espaço entre "o" e "meu", delineando a segmentação correta final "o meu pai".

No que tange à relação entre a informante e a pesquisadora, pôde-se notar que, durante o trabalho de refacção textual, havia, por parte daquela, a certeza de que teria ajuda caso necessitasse, ou seja, de que haveria uma interferência da pesquisadora, vista por ela como uma parceira. Essas interações se tornam visíveis em algumas ocasiões, como, por exemplo, quando a informante está trabalhando em determinada parte do texto, surge uma dúvida, e ela chama pela pesquisadora: “ô (pesquisadora)!”, depois desiste e diz: “É.... não, depois eu vejo com cê isso aqui". Ela se mostra mais determinada a sanar sua dúvida sozinha, pega um livro e o folheia, como se estivesse pesquisando alguma palavra.

Com relação às interferências das ações do cursor do editor de texto na correção de uma palavra, estas foram percebidas pela informante, o que aguçou, também, sua consciência fonológica. Em trecho da versão manuscrita, verificou- 
-se que a aprendiz não observou, em todos os vocábulos, as regras que governam a escrita ortográfica padrão, como mostram algumas inadequações, tais como: início de frase e de parágrafo com letra minúscula ("no dia" "porque nós"); presença da forma verbal "Fui" e do substantivo "Banha" em letra maiúscula inicial no meio da sentença; falta de domínio das regras contextuais regulares e irregulares que determinam o uso do erre forte (nos vocábulos "terível" e "moria") e do "m" antes de "p" e "b" em "tanbem" e "conprada"; presença de hipossegmentação ("oque"); falta de acentuação do advérbio de lugar "la" e grafia do vocábulo estrangeiro shampoo como "xanpoo". Neste último exemplo, por se tratar de vocábulo adaptado ao português a partir do termo inglês, a presença dos dois "o", em vez do " $u$ ", ao final da palavra, na produção da informante, parece ser de fato uma interferência da grafia inglesa certamente já vista por ela nos frascos de "shampoo".

$\mathrm{Na} 2^{\mathrm{a}}$ versão, observou-se a marcação na cor azul das modificações realizadas pela informante; entretanto, pelo texto, só é possível visualizar o que está modificado e não como foram feitas tais alterações e quais foram as estratégias usadas nessa reelaboração. A primeira reelaboração do texto foi a correção da letra minúscula pela maiúscula em início de parágrafo: "no dia" > "No dia"; "porque" > "Porque". Tal procedimento, no entanto, não se verificou em todo o relato, mas em parte dele. Nestas duas correções, parece evidente que a aprendiz está atenta à regra que normatiza o uso da letra maiúscula nos contextos de início de sentença e depois de ponto final. Mesmo assim, as grafias da forma verbal "Fui" e do substantivo "Banha", com letra inicial maiúscula, permanecem inalteradas, evidenciando uma desatenção ou certa liberalidade da informante em relação à violação da regra no trecho em questão. Por estar fora do escopo do presente trabalho, o tópico da defasagem do ensino de língua materna desde os primeiros anos de escolarização não será aqui tratado. No entanto, é digno de nota que muitas dessas dificuldades da informante com a escrita das palavras, especialmente aquelas relacionadas a regras contextuais referentes ao uso do erre e ao de $m$ antes de $\mathrm{p}$ e $\mathrm{b}$, deveriam ter sido sanadas durante o Ensino Fundamental I e II.

Marcações relevantes podem ser observadas com relação aos vocábulos "papel" e "higiênico": as duas formas variantes "papal"/"papel" e "hiegiênico"/"igiênico" convivem pacificamente, não despertando na informante qualquer necessidade de correção. Tais formas oscilantes fornecem pistas do incessante trabalho que teve nossa informante para levantar hipóteses e testá-las em busca da forma autorizada pela ortografia. No caso do adjetivo ("higiênico"), não temos como fazer outras inferências; já em relação ao substantivo ("papel"), suspeitamos que ela possa ter desviado sua atenção na hora da digitação, redigindo, na segunda sílaba, a vogal "a" em vez de "e". Com efeito, nas ocorrências seguintes, 
digita corretamente a palavra. Nesse trecho, também atestamos a colocação do dígrafo "rr", corrigindo o vocábulo "terível" para "terrível", o que não ocorreu com "moria". Outra mudança efetuada diz respeito à palavra "xanpoo", mudada para "shanpoo". Na escrita desse vocábulo, que remete à forma inglesa, não se pode cobrar da informante a aplicação da regra contextual do uso de " $m$ " antes de "p" e "b", uma vez que ela pode ter inferido que tal regra não se aplica à língua inglesa. Já o advérbio de lugar ("la"), sem o acento agudo, foi apagado do trecho.

Nas páginas seguintes, a aprendiz continua seu trabalho de correção dos erros de escrita, mas apenas daquelas palavras em que ela conseguia perceber uma escrita desviante do padrão, conforme se pode observar nos exemplos que se seguem. Em três sentenças, foram realizadas reelaborações das palavras que iniciam o parágrafo:

$$
\begin{aligned}
& \text { "o"> "Oo"> "O" } \\
& \text { "mais"> "Mmaias"> "Mais" } \\
& \text { "ela"> "Eela"> "Ela" }
\end{aligned}
$$

Observando-se o processo de reelaboração da palavra "cabeça", presente no texto, pode-se obter pistas para se compreender as escolhas feitas em cada ação de digitação e retificação realizada com essa palavra. $O$ vocábulo estava inicialmente grafado "caBeça", com o "B" maiúsculo. Verificamos as mudanças implementadas nesta palavra, analisando cada ação: inicialmente se observou a digitação do grafema "c" minúsculo do início da palavra e, a seguir, o seu apagamento. Na mesma palavra, e com uma ação antecipada, digitou-se o "b" (minúsculo), apagou-se o "B" (maiúsculo) e a sequência "eça" simultaneamente. Ao digitar para corrigir e finalizar a grafia da palavra "cabeça", escreve em maiúscula o grafema "B", gerando "caBeça". Ela não percebe o desvio, provavelmente porque o vocábulo estava escrito ao lado de outros que foram apagados na sequência da correção na mesma sentença. Observa-se que não houve o processo de revisão do que ela fez, isto é, a informante não releu, passou adiante sem perceber que deixou para trás um "B" maiúsculo no meio da palavra.

As pistas deixadas na escrita da tela do editor de texto mostram, primeiramente, as ações de inserção e apagamento de segmentos realizadas na sequência em que estas ocorreram no seu trabalho com o texto. Com o arquivo salvo nessa versão final, não se tem ideia de quantas vezes foram realizadas tais ações de reelaboração textual, mas se observam duas formas convivendo pacificamente: uma forma final marcada de azul, com as correções, contemplando a forma anterior riscada, e a nova, corrigida. Para separar a nova forma da antiga, forma-se um traçado no meio das letras apagadas (o recurso da revisão do Word nos ajudou nessa observação). Sendo assim, o que não está traçado é a forma final ou não alterada. Este é um dado relevante, pois o aluno pode ver sua produção na folha (tela) e refletir sobre as duas possibilidades, além de ponderar, mudar 
e fazer quantas tentativas quiser, ou seja, implementar diversas mudanças a depender das hipóteses que tenha levantado. Nesse sentido, percebe-se que o formato digital é vantajoso em relação ao quirografado, pois a folha de papel não retém as marcas da escrita, como ocorre com a forma digitada. Naquela, o que foi apagado está extinto, não se recupera; já nas reelaborações utilizando o editor de texto, caso se decida não aceitar a forma final, com apenas um clique no recurso desfazer digitação ( $\mathrm{Ctrl} \mathrm{Z})$, na barra de ferramentas, poder-se-á fazer o vocábulo reaparecer como outrora estava escrito, desde que isso seja feito antes de se fechar o programa, já que os dados são provisórios.

Há exemplos no relato da informante que mostram a falta de consolidação de alguns conhecimentos sobre o sistema ortográfico da língua. É o caso da escrita da palavra "deslunbrada", em que a informante não percebe a existência do ambiente propício à aplicação da regra de uso do "m" de fim de sílaba. Verifica-se também falta do domínio dos contextos de uso dos erres, oscilação quanto ao uso do pronome reflexivo ("mi"/"me") e muitas incertezas em relação ao contexto de uso do fonema /s/ e suas múltiplas possibilidades ortográficas. Conquanto haja todas essas dúvidas por parte da informante, é possível perceber, ao longo de toda a versão digitada, seu desenvolvimento no domínio das nuanças que caracterizam a escrita padrão. Constatamos, por exemplo, que houve correção de nomes próprios grafados com letra inicial minúscula; mudança de letra minúscula para maiúscula depois de ponto e em início de sentença; troca do grafema "g" por "q" em vocábulos do tipo "guando"; maior percepção da diferenciação dos tempos verbais marcados por "-ão" e "-am".

Para além da contabilização de erros e acertos, consideramos que os dados obtidos corroboram a afirmação de vários autores de que, quando o aprendiz escreve, reelabora, aceita ou não a marcação do software, escolhendo a melhor solução para a resolução de um problema, está, ao mesmo tempo, trabalhando ativamente na construção e reconstrução de seu aprendizado e desenvolvendo uma atuação ativa, crítica e reflexiva sobre sua ação (ALMEIDA, 2003; ROCHA, 2008; VALENTE, 1991, 1997, 1999). Ademais, há que se considerar que, em uma atividade de elaboração e reelaboração de texto, usando-se uma ferramenta digital como instrumento auxiliar no processo de alfabetização, o aluno poderá:

(i) ousar, criando e testando hipóteses, até encontrar a forma ortográfica padrão ou aquela que ele considera ser a correta;

(ii) receber o feedback positivo quando a palavra estiver corretamente grafada;

(iii) explorar os erros como caminho para potencializar a aprendizagem; 
(iv) comparar os vocábulos como estavam escritos antes e depois da correção, visualizando as duas possibilidades na tela;

(v) refletir criticamente, procedendo a uma auto avaliação;

(vi) desenvolver a percepção da existência de outros erros, outrora despercebidos, durante seu processo de aprendizagem da base alfabética.

\section{Considerações finais}

Nosso objetivo com a amostragem de análise qualitativa do texto aqui apresentada foi, antes de tudo, o de contribuir para a reflexão sobre o papel do recurso de revisão do editor de texto usado, o Word, por um sujeito aprendiz de EJA durante o processo de digitação de sua autobiografia. Esse recurso foi de grande valia para a elucidação das nuanças envolvidas em cada decisão ortográfica tomada pelo sujeito aprendiz. No entanto, a captação de todos os passos da cadeia que compõe o processo em questão apenas foi possível pelo uso do software Camtasia, que captura a tela e os movimentos feitos no texto durante sua digitação.

Verificamos que houve influência positiva do uso do computador sobre o processo de aprendizagem de nossa informante, favorecendo o aprimoramento de sua consciência fonológica e consequente repercussão em seu desempenho ortográfico durante a elaboração do texto. Observou-se, por exemplo, que, ao ler o texto em voz alta, durante o ato de escrita, ela se mostrou, recorrentemente, incomodada com a forma vocabular escrita na tela, conforme evidenciado em vídeo Camtasia. Essa percepção dos erros ortográficos ocorreu devido ao desenvolvimento de sua consciência fonológica, o que a impulsionou a corrigi-los, embora sua percepção se detivesse apenas no registro de seletivos erros em alguns vocábulos, não atentando para as formas oscilantes da escrita que se desviavam da norma ortográfica.

Tais ganhos falam por si sós em favor da necessidade da inclusão digital de professores alfabetizadores a fim de que possam lançar mão de tecnologias que potencializem uma avaliação longitudinal e uma compreensão dos processos de aquisição da escrita durante os diversos estágios de letramento. O uso das novas tecnologias permite, também, a consideração de fatos singulares da escrita do aluno durante sua produção textual. Tais fatos evidenciam o percurso individual do sujeito, complementando assim informações sobre suas vivências com a língua que manipula e sua relação com as regras ortográficas regulares e 
irregulares. Assim, parece claro que instrumentalizar o professor alfabetizador com novas tecnologias é parte importante de sua capacitação para uma atuação eficaz na mediação do processo de letramento, possibilitando-lhe um mapeamento mais fidedigno do percurso de cada alfabetizando e permitindo-lhe intervenções oportunas suprindo lacunas, sanando dúvidas e atenuando dificuldades.

Nesta pesquisa, o olhar aguçado sobre o uso do computador pelo informante-aprendiz permitiu conjugar duas percepções do mesmo processo: (i) a do professor, que tem acesso à vida do aprendiz por meio de sua escrita, e (ii) a do aluno, que pode analisar o seu próprio processo de aprendizagem. Nessa comunhão de perspectivas, o computador é ferramenta importantíssima para a avaliação diagnóstica processual do aluno pelo professor. Tal posição corrobora a crítica de Costa et al. (2003), ao pontuar que muitas vezes a ação mecânica de escrever e o decodificar de letras em um texto são confundidos com verdadeiros atos de escrita e leitura, dando-se mais destaque ao produto do que ao processo dinâmico de alfabetizar. Assim, ao se avaliar apenas o resultado de um processo de alfabetização, limitamos o diagnóstico sobre o nível real de desenvolvimento cognitivo do aprendiz, pois se tiram conclusões sem levar em consideração aspectos relevantes e dinâmicos desse processo.

Uma avaliação diagnóstica processual do percurso da alfabetização, por meio de gravações da refacção textual realizada no computador e captada por um aplicativo que grava a tela e os movimentos realizados pelo usuário no teclado, trouxe dados cabais que mostram o percurso de sua aprendizagem. Ou seja, a gravação de movimentos na tela proporcionou a captação de todo o trabalho epilinguístico do sujeito aprendiz sobre sua produção textual, atribuindo significado à inelegibilidade de um vocábulo, à escrita truncada, às substituições, aos apagamentos, enfim, aos erros ortográficos presentes no texto. Assim, pôde-se lançar luz sobre a própria concepção de escrita do informante dando relevância às hipóteses testadas e atestadas por ele durante a construção do texto.

Todos esses dados são ricos em informações relevantes, cuja análise permite pensar em novas abordagens de ensino que envolvam, com fins didáticos claramente delineados, o uso de uma tecnologia assertiva, como o computador, no processo de alfabetização e letramento. Por fim, neste artigo, buscamos ressaltar a importância de se explorar recursos tecnológicos que contribuam para o desenvolvimento e aprimoramento da escrita, mormente para o resgate do trabalho epilinguístico da refacção textual. Tal resgate se configura como fundamental para a compreensão não apenas dos produtos ortográficos engendrados, mas também de cada hipótese de escrita aventada pelo sujeito aprendiz em cada ponto da cadeia processual que compõe sua trilha de aprendizado das intrincadas relações entre letras e sons e daquelas existentes entre os vários elementos cognitivos que compõem as habilidades de leitura e escrita. 


\section{REFERÊNCIAS}

ADAMS, M. J. et al. Consciência fonológica em crianças pequenas. Porto Alegre: Artmed, 2006.

ALMEIDA, M. E. B.; PRADO, M. E. B. B. Criando situações de aprendizagem colaborativa. In: VALENTE, J. A.; ALMEIDA, M. E. B.; PRADO M. E. B. (Org). Internet e formação de educadores a distância. São Paulo: Avercamp, 2003.

ANGRIST J.; LAVY, V. New evidence on classroom computers and pupil learning. The Economic Journal, n.112, p.735-765, 2002.

ARAÚJO, A. L. O. S. Um olhar pela perspectiva linguística-viés fonológico-dos erros ortográficos presentes em um relato autobiográfico, manuscrito e digitado, escrito por um adulto: um estudo de caso. Tese em Linguística Aplicada, Universidade Federal de Minas Gerais, Belo Horizonte, 2014.

ARMSTRONG, A.; CASEMENT C. A criança e a máquina. Porto Alegre: Artmed, 2001.

BRYANT, P. E.; BRADLEY, L. Problemas de leitura na criança. Porto Alegre, RS: Artes Médicas, 1987.

CAPOVILLA, A. G. S.; CAPOVILLA, F. C. Efeitos do treino de consciência fonológica em crianças com baixo nível sócio-econômico. Psicologia: Reflexão e Crítica, Porto Alegre, v. 13 , n. 1, p. 7-24, 2000.

COSCARELLI, C. V. O uso da informática como instrumento de ensino e aprendizagem. Revista Presença Pedagógica. v.4, n. 20, mar./abr., 37-45, 1998.

COSCARELLI, C. V. Jogos digitais e novas interfaces para alfabetização. In: Anais do XV Endipe - Encontro Nacional de Didática e Prática de Ensino (CD). Belo Horizonte, FaE/UFMG, 2010a.

COSCARELLI, C. V. Tecnologias digitais no ensino. In: Anais do XV Endipe - Encontro Nacional de Didática e Prática de Ensino (CD). Belo Horizonte, FaE/UFMG, 2010b.

COSTA, M. S; PALÁCIO. P. P. G.; PAULUCCI, G.. A contribuição do uso do computador na aquisição da linguagem escrita por jovens e adultos em processo de alfabetização. 2003. Disponível em: http://www2.anhembi.br/publique/media/portal/top_educacional_2003_artigo.pdf. Acesso em: 01 jan. 2018.

DWYER, T. et al. Desvendando mitos: os computadores e o desempenho no sistema escolar. Educ. Soc. v. 28, n.101. Campinas, set./dez. 2007. Disponível em: http://www. scielo.br/scielo.php?script=sci_arttext\&pid=S010173302007000400003\&lng=en\&nrm =iso. Acesso em: 04 fev. 2018.

GONÇALVES, B. H.. O uso do computador, a alfabetização e a pós-alfabetização: o que dizem educandos/as do MOVA. São Carlos: UFSCar, 2007. 
MARINHO, A. R. P.; ARAÚJO, A. L. O. S.; THOMOPOULOS, M. S. F. Aspectos articulatórios e fonológicos envolvidos na aquisição da linguagem de uma criança de 5:1 anos: um estudo de caso. Letras de Hoje. Porto Alegre, v. 47, n.1, p. 84-92, jan./mar. 2012.

PAPERT, S. The Children's Machine: Rethinking School in the Age of the Computer. New York: Basic Books, 1993.

ROCHA, S. S. D. O uso do Computador na Educação: a Informática Educativa. Revista Espaço Acadêmico, n. 85, jun. 2008. Disponível em: http://www.espacoacademico.com. br/085/85rocha.htm. Acesso em: 06 jan. 2018.

SETZER, V. W. A Critical View of the "One Laptop per Child” Project. Disponível em: http://www.ifip.org/wcce2009/proceedings/papers/WCCE2009_pap73.pdf. Acesso em: 11 dez. 2018.

SPRIETSMA, M. Computers as pedagogical tools in Brazil: a pseudo-panel analysis. Center for European Economic Research (ZEW), Mannheim, April 2007. Disponível em: ftp://ftp.zew.de/pub/zew-docs/dp/dp07040.pdf. Acesso em: 11 dez. 2018.

VALENTE, J. A. Liberando a mente: computadores na educação especial. Campinas: Graf. Central da UNICAMP, 1991.

VALENTE, J. A. O uso inteligente do computador na educação. Pátio, ano 1, n. 1, mai/ jul., p. 19-21, 1997.

VALENTE, J. A. (Org). O computador na sociedade do conhecimento. Campinas, SP: UNICAMP/NIED, 1999.

Texto recebido em 15 de outubro de 2018. Texto aprovado em 17 de novembro de 2018. 